\title{
Role of Symbolic Interactionism in Marketing Communication Planning at Local Cosmetic Company
}

\author{
Sinthia Delvi Alexander ${ }^{1}$ Muhammad Adi Pribadi ${ }^{*}$
}

\author{
${ }^{1}$ Faculty of Communication Science, Universitas Tarumanagara, Jakarta 11440, Indonesia \\ *Corresponding author. Email: adip@fikom.untar.ac.id
}

\begin{abstract}
One of the forms of communication is through digital communication on the internet. The internet is widely used by companies as a medium to market their products or services. However, not all companies are able to carry out a good marketing communication planning process to achieve company targets. Especially with the local cosmetic industry, where the competition is getting tougher. The local cosmetic market is growing more and more, which every year has a significant market increase. Therefore, every company must be able to compete through advertisements that are created to survive. The process carried out by the company in advertising goes through many elements of communication in it, one of which is described in Symbolic Interaction theory. This study discusses how symbolic interactions play a role in marketing communication planning at Mad For Makeup Indonesia. This research is based on Symbolic Interaction theory refined by George Herbert Mead and Marketing Communication Planning theory by Personal, Suganda, Venus, and Susanto. The approach used is the descriptive qualitative case study method. Research sources were owners and employees of the Mad For Makeup company to obtain various types of data, namely primary data and secondary data through interviews, literature study, and documentation. Data obtained through the processing, analysis, presentation, and verification of the validity. The results also show that Mad For Makeup carries out a marketing communication planning process, namely business objectives, strategy, tactical, implementation, monitoring, and evaluation. This process contains elements of communication from Symbolic Interaction theory to support the planning process within the company.
\end{abstract}

Keywords: Symbolic Interaction, Marketing Communication Planning, Makeup Company, Advertisement

\section{INTRODUCTION}

Communication itself also develops along with the development of civilization. It can be seen the difference from the communication process which can now be carried out without any distance obstacles. The communication process is also facilitated by the existence of internet access which provides various communication media for use by users. This global development has an impact not only on developed countries but also on developing countries such as Indonesia. Based on data from Internet World Stats released in March 2019, Indonesia has reached the fifth country with the highest number of internet users with 143 million people. There was an increase of $7.063 \%$ of internet users in 2000, which was only 2 million people. This rapid increase indicates Indonesia's position as the third developing country that has succeeded in reaching the top five positions in the high population of internet users in various countries in the world.

One of the activities aimed at large numbers of people is marketing. According to Stanton [1], marketing is a system designed for a business or business activity to plan, determine prices, promote, and distribute goods or services that are useful for satisfying the desires of existing or potential consumers. Marketing is important for a company to achieve certain goals. Marketing that is done well can also have a positive impact on a company. This can be reflected in the increased number of sales, as well as strong selling. Therefore, marketing must be well planned in order to be executed and produce the impact that the company expects. It is during the planning process that the role of communication can be reviewed through Symbolic Interaction theory. Symbolic Interaction Process can be found in human interaction, therefore in planning advertisements, Symbolic Interaction plays an important role [2].

The emergence of an awareness of the importance of marketing communication planning has also increased competition in various Indonesian industries. One of the industries with fierce competition and a wide market is the cosmetics industry. According to the Ministry of Industry of the Republic of Indonesia, there are 797 large industrial cosmetic companies and small and medium industries in Indonesia. This number represents a growth of $7 \%$ from the previous year. The beauty and self-care cosmetics market in Indonesia is estimated to reach US \$ 6.03 billion. This 
figure is also predicted to reach US \$ 8.46 billion in 2022. Based on research conducted by the Indonesian Digital Marketing Association which was conducted on the marketplace until January 7, 2020, there is a huge online market [3].

This rapid development is also considered to have ample room for growth. According to data obtained by the Ministry of Industry of the Republic of Indonesia, the average amount of money spent by Indonesians for cosmetic and personal care needs is US \$ 20 per capita. This shows that there is still room for the cosmetics and beauty industry to grow. When compared with other Southeast Asian countries, the average Thai cosmetics spending money is US \$ 56 per capita, and US \$ 75 per capita for Malaysians [4].

Therefore, the competition between the local cosmetic market is getting tougher in maintaining their respective companies and brands. One of the local cosmetic companies that has succeeded in making its way in this competition is Mad For Makeup Indonesia. The presence of Mad For Makeup in its first year has received various achievements. One of them is by selling 18,000 beauty sponges. Mad For Makeup has also received several nominations from local platforms, namely the Sociolla Awards, Female Daily Awards, and Beauty Fest Asia Awards. This nomination was achieved through product innovation and marketing. Not only that, Mad For Makeup Indonesia is also one of the local cosmetic companies that Gojek invited to participate in the Gojek Accelerate program which aims to incubate companies that have the potential to develop. Mad For Makeup has also been featured in various online news media such as Daily Social, Female Daily, Kompas, and many more. This was achieved due to the success of various marketing campaigns carried out with tangible results in less than three years.

Based on the background that has been described, the researcher wants to know about the role of Symbolic Interaction in the local cosmetic company Mad For Makeup Indonesia in planning marketing communications. Therefore, the title of this research is "The Role of Symbolic Interaction in Marketing Communication Planning".

\subsection{Related Work}

According to the generation type of assumptions, we divided the existed work into two categories.

\subsubsection{Symbolic Interactionism}

On the existing theory of Markov Decision Process (MDP) Symbolic interaction is an understanding that can be reflected in every aspect of human life. Manusa interacts every day through communication using symbols as a means of exchanging meanings. George Herbert Mead said in West and Turner's book that this is due to symbolic interaction theory which discusses ideas and concepts about human beings in the process of interacting with the surrounding community so that verbal and non-verbal symbols appear in the process of forming meaning. The interaction process arises from two individuals who communicate to convey a common understanding and understanding of a conveyed meaning [5].

Symbolic interaction theory according to Mead is a theory that discusses human social life in various perspectives of subjective aspects. Humans are seen as both subject and object at the same time. The thought that is the basis of this theory is human behavior caused by social meanings and processes to their surroundings.

Three important concepts in symbolic interaction theory as described by Mead in the book Mind, Self, and Society are the main concepts that are interrelated with one another. The concept of Mind, Self, and Society is part of a general process called social action. Quoted from Littlejohn \& Foss, this social action begins with encouragement, individual perceptions and the delivery of meaning, repetition in the individual's mental state, consideration of alternative messages, and meaning refinement. Therefore, based on West \& Turner's [5] book the concept of Mind, Self, and Society is further explained as follows.

According to Mead [5], the concept of mind is an individual's ability to use symbols conveyed in social interactions that have the same social meaning. Social interaction can also develop an individual's ability to study symbols in communication messages by indicating the capacity for themselves, who and what they are, the objects around them, and the meaning of objects for them.

In the process of social interaction, individuals use verbal and non-verbal symbols to convey their thoughts. That is why humans realize that by interacting with one another, an individual can give rise to language through the symbols conveyed. This language has a significant symbol, which is a symbol that has a meaning that is generally understood and agreed upon by many individuals.

When an individual accepts and uses a variety of existing symbols, the individual performs a process of interaction with himself to identify, name, and interpret these symbols. This is called the concept of thought (thought) which is a conversational process from within humans. Conversations in humans are free from social influences or interactions with other individuals. Therefore, man can only rely on himself in the thought process.

After going through the thought process, humans implant this meaning into the brain's memory to enrich the meaning of the symbols that have been learned. This allows humans to perform activities called role-taking, where individuals have the ability to think and place their own images in the minds of others. This provides an opportunity for humans to imagine an event from the perspective of others. Role taking is carried out symbolically in human thought, and this ability is one of the important activities that is explained from the understanding of thought in Symbolic Interaction theory. 
The concept of self according to Mead refers to an ability or capacity and experience that allows humans to become objects for. This is possible because humans at the self stage have the capacity to see themselves from the point of view of others. The ability of humans to become objects for themselves arises when humans are able to take on the role of others in the social environment where they are.

The process of taking roles in this social environment causes individuals to internalize the norms of the groups they follow. Starting from a small group, namely family, peers, community, and national groups. When humans socialize with other people in the group, this process is carried out based on the norms held by the group and allows individuals to be socialized. Humans are also faced with different perspectives. When group members communicate their point of view, humans can see their own looking glass self from the point of view of others. The three principles regarding self-mirror conveyed by Cooley [5] are as follows:

1. Humans imagine themselves in the judgments of others.

2. Humans imagine other people's judgments of their appearance.

3. Humans have an emotional response, namely feelings of pride or pain against the assessments they receive.

These three principles can make humans know themselves, how humans see themselves, and how humans give labels to themselves. According to, this process produces the Pigmalion Effect (Pygmalion Effect) in which humans take actions based on the expectations or expectations of others. Humans try to meet other people's expectations.

The self-concept according to Mead can also be said to be something that is referred to in ordinary conversation through a single person pronoun and has a subject focus, namely I (I), Me (daku), and Myself (myself). Subject I or I is the individual who becomes his true self. The subject Me or daku is an individual who acts as an object towards I or me. Myself subject or myself is an individual who responds to himself as an object.

The final stage in the process of internalizing symbolic interactions is through society. Society according to Mead is a network of social interactions created by humans where members place themselves using symbols that have been learned. Humans use the meaning of actions carried out by themselves and others through symbols used by the community groups they follow. Community members also help build symbols that can be understood by each member through continuous interaction. Individuals who are members of these community groups because of their conscious behavior or actions based on personal desires.

The concept of society itself is a collection of various social aspects that exist in human life. The social aspects mentioned include religion, ethnicity, nationality, culture and religion. Therefore, the interaction of the individual with the society around him is important for the formation of that individual's self-concept. There are two types of society mentioned by Mead, namely the special people (significant others) or the general public (generalized others). Special societies or significant others are other people or communities whose presence is considered significant for that individual such as family, close friends, and others. Individuals seek validation from a special society because of the significance they consider important. While the general public or generalized others are other people or communities whose presence is general and does not have as much significance as a special society. The general public exists to provide information for individuals about social roles, social rules, and shared attitudes. There is hope or expectation that society has towards its members, and each member can react to these expectations through their actions.

Both types of society play an important role in shaping individual self-concept. If the thoughts and self of individual members of society develop, it will affect the development of society itself. Vice versa, if society develops, this development can affect the members in it. It is a unity, so that self, mind, and society are a part that cannot be separated from one another. Therefore, the social structure which is dynamic in nature arises from the continuous development of each member of the group.

\subsubsection{Marketing Communication Theory}

Marketing communication planning according to Personal, Suganda, Venus, \& Susanto (2018) [6] is the result of business interest planning which can produce a communication concept that can be used to target targets clearly and precisely. There are six indicators of success in marketing communication planning, namely as follows:

1. Business Purpose

The business objectives of each company are made to generate maximum profit and to increase the progress of the growth of the company itself.

2. Strategy

The strategy is an effort or plan arranged in such a way by the company to achieve a goal. Companies can develop several strategies from five strategic aspects, namely:

a. Communication Purpose

There are two communication objectives that can be achieved in marketing communication planning activities, namely brand recall and brand recognition. Brand Recall according to Prashar [7] is how good a customer can remember a brand when faced with certain situations. Brand recall can be grown on customers who already have knowledge or experience with the brand. Meanwhile, according to Keller, brand recognition [7] is how fast customers can recognize and differentiate a brand when faced with elements of the brand such as logos, slogans, and so on. Brand Recognition can occur because humans tend to be able to identify things that can be recognized. When a brand recall is a technique that is used indirectly to customers, brand recognition is carried out in direct ways or methods with customers.

b. Target Market 
A target market is a group of people belonging to the same group who are the points of marketing and sales efforts. A company's products or services must adjust to the market they want to target, so knowing that market is very important in maintaining the continuity of marketing activities.

c. Competitors

Competitors or competitors are other entrepreneurs engaged in similar fields or lines of business with the same target market. Competitors or competitors can be categorized in terms of differences, namely strong and weak competitors. In planning a marketing strategy, the company must analyse the strengths, weaknesses, opportunities and threats of competitors. This is done so that the company can find out its strength points against these competitors.

d. Communication Theme

The communication theme is the unity of the message that will be conveyed through marketing communication planning. The theme of communication will determine the visual direction and writing that is delivered. Communication themes are important in determining the right marketing communication planning strategy. The communication theme must also fulfill the communication objectives that were predetermined. Information regarding competitors' weaknesses and strengths also affects the communication theme chosen to ensure that the theme carried has strengths against competitors.

e. Communication Channels

The communication channel is the channel of choice for conveying predefined communication messages. Communication channels can be all areas that can convey messages. One of them is print media, billboards, magazines, television, radio, posters, leaflets, and billboards. In this digital age, one of the most widely used communication channels is online through social media.

3. Tactical

Tactical is an action that is carried out from a strategy that has been carefully made. Tactical that will determine the effectiveness and success of the implementation of planning activities.

4. Implementation

Implementation is implementing actions carried out based on tactical strategies that have previously been carefully and thoroughly prepared. During the planning implementation, monitoring or monitoring will be carried out.

5. Monitoring

Monitoring is an activity to monitor the implementation in the implementation stage which is carried out in stages to obtain information that will later be used in the evaluation phase to assess whether the strategy has achieved the specified results or business objectives.

6. Evaluation

Evaluation is the stage of assessing the results of planning activities that have been carried out with the aim of knowing the advantages and disadvantages of implementing the planning with the aim of correcting mistakes and avoiding the same mistakes in the future.

\subsection{Paper Structure}

This research organizes as follows. Section 2 introduces the background of the research that will be conducted upon. Section 3 will elaborate the methods that this research is held. Section 4 The framework is elaborate with the findings and are concluded in section 5. Section 6 presents acknowledgement with references through section 7 .

\section{BACKGROUND}

This research will be conducted upon the theories of Symbolic Interaction by George Herbert Mead as well as the Marketing Communication Planning theory by Pribadi, Suganda, Venus and Susanto. This study uses a qualitative research approach where according to Moloeng [8], a descriptive qualitative research is a study that aims to understand the phenomena or events experienced by the research subject that involves various aspect such as perception, action, motivation, and behaviour that are described through words in a context determined by the natural method. Therefore, allowing the researcher to describe the existing phenomena while not trying to look for nor explaining the relationship between the existing variables.

\section{METHODS}

Meanwhile, the case study method is chosen to encapsulate the information from the research. Yin [9] concluded that a case study is one of the various research methods for social science. Being the suitable way for answering how and why questions. This method is used upon the research subject. The research subject itself being the sources or informants who are the core objectives of the research or parties that provide information regarding the relevant problem. Therefore, the sources or informants used in this study are company owners and employees who are active in the strategy, business development, and marketing field. On the other hand, the research object is a material nor an individual figure that will be analyzed from the selected research subject. This study's object is the local cosmetic company, Mad For Makeup Indonesia.

The data collection method used in this research is through 2 sources, namely primary and secondary data. These two sources were obtained through various methods. Namely interviews, documentation, and archival records. Afterward, the data obtained by the researchers must go through processing and analysis to be easily conveyed.

First, the data obtained is recorded carefully, clearly, and completely. The author summarizes the information into main data with a focus on the problems of the phenomenon that's being sought after. Secondly, the data that has gone through a reduction process will be presented with brief descriptions, charts, flowcharts, and the likeness of it. The data is presented to make it easier for researchers to 
understand the phenomena that occur and be able to plan the next research process.

Lastly, the data that has been reduced and presented must go through a validity technique to determine whether the data has real substance, enabling it to be held accountable for the said research. In this study, the researcher conducts the data validity by analysing the collected data and handling it back to the source or informant to confirm the data's truth.

\section{FINDINGS AND DISCUSSIONS}

Mad For Makeup Indonesia is a start-up company engaged in cosmetics. Tony Tan Zhi Han and dr founded this company. Shirley Mesela Oslan in April 2017. Mad For Makeup also has a slogan with the name "Rebel Beauty Company". This slogan means that this beauty company is like a rebel, wanting to escape from the beauty business flow in general. Mad For Makeup in fulfilling its goal of becoming the number one cosmetics company has a vision and mission to achieve that goal. Mad For Makeup's vision is to democratize beauty. This can be done through their mission by creating high-quality products at affordable prices to achieve a beauty that easily and practically provides confidence through community and creativity. As a process of reaching their audience and growing the company, Mad For Makeup also undertakes marketing communications planning.

When planning marketing communications, each member of the Mad For Makeup Indonesia team also interacts with one another and builds a cohesive interaction. These interactions can be analyzed using the Symbolic Interaction theory proposed by Mead. In building a corporate culture, Mad For Makeup Indonesia has various jargon or terms used. One of them is the term 'rebels' which is used to define the community and audience of Mad For Makeup itself. Despite the particular meaning meant by Mad For Makeup, the word "rebel" refers to rebels. The word 'rebel' is also used regularly by every employee at Mad For Makeup Indonesia, indicating a significant symbol in accordance with Mead's theory of symbolic interaction.

One other activity that is often carried out in building a company culture is by holding weekly meetings where each employee tells what has been done and what was learned in that week, and what will be done in the following week. This provides an opportunity for each individual to be able to understand what is happening with his coworkers and gives him the opportunity to take on a role and get better work unity. This is also in accordance with the concept of role-taking proposed by Mead in Symbolic Interaction theory. Every employee has the right to express their opinion on what is done with each other, and this provides space for everyone to convey and communicate their point of view. This is in accordance with the concept of looking glass self by Mead, where humans can see a mirror of themselves from the perspective of others.

These evaluations can provide knowledge to employees at Mad For Makeup about themselves. Every employee is increasingly able to learn to recognize himself. Therefore, there will be labels or individual opinions about themselves. This becomes the basic motivation for employees to do their jobs according to the team's. Individuals are motivated to meet these expectations. This is where it can be seen that Mead conveyed the Pigmalion Effect or Pygmalion Effect. The Mad For Makeup team's unity is closely guarded because of the awareness that a good team will produce good work. Therefore, every employee is encouraged to interact intensively with one another in order to build a good internal working relationship (Littlejohn \& Foss: 2010) [10]. In the end, each employee will do things that are mutually agreed upon. This is in an effort to reach significant others or special societies. The presence of a special community is important because it can provide validation and provide a more important role and response. Team members, including company owners, fall into this special community category.

Apart from the presence of a close team, Mad For Makeup also has an external environment that provides information about the business environment's social structure. None other than called generalized others or the general public. The presence of generalized others does not have the same significance as significant others, but they still play a role in the company's development. One of the generalized others for Mad For Makeup is with production companies, distributors, online sales platforms, and various marketing partners who have collaborated.

The importance of good teamwork is part of Mad For Makeup's goal by creating a campaign related to beauty that can make an impact on the company and its own audience. Therefore, Mad For Makeup is planning a marketing communication to achieve this well. The first stage, Mad For Makeup must determine what the purpose of the campaign is, where there are several things, namely product releases, routine campaigns, or specific projects. After the head of the Business Development division determines the activities to be carried out next that require marketing communication planning, he will create and provide a brief of these activities to the strategic division, where the strategic division is in charge of determining the marketing communication strategy. After getting a brief of the main objectives, the strategic team will determine how strategic tactics are right for running the campaign to fit the business goals. The strategic team will collect data through research to find out what problems the audience is facing. The data collection process is carried out internally and externally. When done externally, it is to obtain information from outside parties or audiences. If done internally, the strategic team will seek information from literature studies. Both of these studies also aim to examine the SWOT of the campaign being carried out. Knowing who their competitors are can give Mad For Makeup powerful information in determining the right strategy to win.

After getting the right data, the strategic team will determine the right problem, a solution that can solve the problem. Of course, with the data collected, Mad For Makeup's strategic team can also determine the appropriate target market. The solution is an extension of the insight or information obtained and evaluated. The right 
communication solution or theme will be conveyed via multiple communication channels, or touchpoints. These touchpoints can use various media such as Instagram, Twitter, Tiktok, Youtube, Ads, and so on. All the final strategies will also be included in a central document that can be accessed by all teams from various divisions. This document will serve as guidelines for the work of the entire team. This document, which is called the Central Business Description or abbreviated to CBD, contains all information and details from the beginning of the research process, strategy determination, communication messages, and communication channels. There are also targets that must be achieved in the form of reach, impression, visit, sales, and conversion of each activity undertaken.

After getting the right strategy, the Mad For Makeup team must create the right way to execute the planning strategy well. A mature strategy will only give appropriate results if it is equipped with a strong and disciplined tactical system. This is what the Mad For Makeup team stands for. This method of execution will determine the effectiveness and success of implementing planning activities. When the tactical process has been declared, what must be done next is execution. The execution process is important to do well and optimally. Therefore, every division head must ensure that the execution is carried out properly. Starting from the execution of the preparation to the execution of the activity, everything must be in accordance with what has been planned and on time.

During the campaign execution process, there was supervision from the data team to obtain the value or results of the campaign being carried out. These results can take many forms. When viewed from an Instagram point of view, the data team will pull data about reach, impressions, followers, likes, comments, and so on. This data collection is seen from the period before the day of the implementation, until the seventh day of the execution. This is to ensure that the data that is owned is complete for evaluation. The importance of collecting data during the monitoring process is to see how the results are obtained from the ongoing execution. These results will be used as evaluation material in the next stage. The fulfillment or failure of a campaign is judged by the results obtained. Therefore, results are very important in this context.

Entering the final stage of the entire campaign, there must be an evaluation. At this stage, Mad For Makeup evaluates twice, namely after three days of implementation, and after seven days of implementation. These two stages of evaluation are very important because they have their respective functions. The first evaluation stage carried out on the third day was to rearrange the strategic campaign that will be carried out next. The ongoing campaign will be assessed for its effectiveness and performance for three days. If improvement or progress is needed in a certain aspect, it will be rearranged on the third day. Judging from which side Mad For Makeup can develop from activities that have been running. The second evaluation stage which was carried out on the seventh day was to evaluate the campaign as a whole. Starting from planning, division of tasks, execution, monitoring, campaign results, and goal achievement. This second evaluation stage is usually carried out by holding meeting sessions with each division. In this second evaluation stage, the data analyst must also convey the results of data collection related to errors that occurred during the campaign process. Not only does it stop at the evaluation, but Mad For Makeup also looks for solutions to improve the next campaign.

\section{CONCLUSIONS}

Based on the results of the research conducted, Symbolic Interactions play an important role in shaping the culture of Mad For Makeup Indonesia. This good culture will help all employee staff in planning marketing communications to further develop the company and increase competition. The marketing communication planning process carried out by Mad For Makeup starts with determining business goals, then continues with determining the right strategy to achieve these goals. A mature strategy is followed by devising the right tactics in executing this strategy. The next process is to carry out implementation, followed by monitoring during implementation. After the entire execution process has been carried out, an evaluation is conducted to assess marketing communication planning success and determine follow-up actions. The whole process will only run well because the interaction between staff is built into a good corporate culture.

\section{ACKNOWLEDGMENT}

This work is supported by God Almighty because for his blessings, this research can be carried out. The author would also like to thank the author's family, lecturers and supervisors at the Faculty of Communication, Universitas Tarumanagara, friends, and co-authors for supporting the author in conducting this research.

\section{REFERENCES}

[1] Margaretha, S., Widayatmoko, W., \& Pribadi, M. A. Analisis Komunikasi Pemasaran Terpadu PT. Cubes Consulting dalam Membangun Brand Association. Jurnal ASPIKOM, 1(5), pp. 455-462, 2012.

[2] Morrisan, M. A. dkk, Teori Komunikasi Massa, media, budaya, dan masyarakat, Ghalia Indonesia, Bogor, 2013

[3] Data Produk Kecantikan Terlaris Di E Commerce: DIGIMIND, Retrieved December 1, 2020, from https://digimind.id/data-produk-kecantikan-terlaris-die-commerce/ 
[4] Kemenperin: Perubahan Gaya Hidup Dorong Industri Kosmetik, https://kemenperin.go.id/artikel/ 21460/ Perubahan-Gaya-Hidup-Dorong-Industri-Kosm etik

[5] Ilhaq, Abdillah, Perencanaan Komunikasi Pemasaran Di Era Pandemi (Studi Kasus Rumah Sakit Sukmul Sisma Medika Tanjung Priok), Skripsi. Jakarta: Universitas Tarumanagara, 2020.

[6] Pribadi, Muhammad Adi., Suganda, Dadang., Venus, Anter., \& Susanto, Eko Harry, Dinamika Perusahaan Periklanan Indonesia: Studi Kasus Komunikasi dan Budaya Organisasi Dwi Sapta IMC dan Fortune Indonesia, Disertasi Universitas Padjajaran, Bandung, 2018.

[7] Khurram, M., Qadeer, F., \& Sheeraz, M, The Role of Brand Recall, Brand Recognition and Price Consciousness in Understanding Actual Purchase, Journal of Research in Social Sciences, 6(2), pp. 219$241,2018$.

[8] Moelong, L. J. Pengantar Metode Penelitian Kualitatif, Remaja Rosda Karya, Bandung, 2013.

[9] Yin, Robert K. Studi Kasus: Desain \& Metode, Rajagrafindo Persada, Jakarta, 2014.

[10] Littlejohn, S. W., \& Foss, K. A, Theories of human communication, Waveland press. USA, 2010. 